\title{
International Federation of Gynecology and Obstetrics Global Declaration on Cervical Cancer Elimination*
}

\section{FIGO World Congress}

Address for correspondence International Federation of Gynecology and Obstetrics, Suite 3 - Waterloo Court, 10 Theed Street, London, SE1 8ST, United Kingdom (e-mail: figo@figo.org).

The FIGO encourages countries to reach all eligible girls and women through comprehensive cervical cancer control through a life course approach: including vaccination against human papillomavirus (HPV), screening and treatment of cervical precancerous lesions, early diagnosis, and timely treatment of invasive cancer and palliative care.

As the leading professional society in the field of gynecology and obstetrics, the FIGO has a large membership with global reach that can bring their expertise to the global call to eliminate cervical cancer in the following key areas:

- the global advocacy movement

- the need to address health workforce knowledge and skills gaps

- improvement of community engagement and health literacy

- technical assistance for global guidance

- leverage of our collaborations and partnerships

For too long, too many of the poorest and most vulnerable women have suffered from this highly preventable and curable form of cancer. With significant strides made in reducing maternal mortality, women who are saved now risk dying later from cervical cancer.

The present FIGO declaration is a commitment to collaborate on the global effort to accelerate national action towards the elimination of cervical cancer. This is to make cervical cancer a story of the past and to safeguard the human rights of all women everywhere to health and wellbeing, no matter where they live.

\section{We Declare}

We, the participants of the XXII FIGO World Congress of Obstetrics and Gynecology, held in Rio de Janeiro between 14th and 19th October 2018, hereby declare that we will 
work collaboratively to scale up interventions with the aim of eliminating cervical cancer as a public health concern.

In line with cervical cancer elimination priority actions:

- Introduce and scale-up HPV vaccination to achieve high coverage among girls by the age of 15 years old

- Introduce and scale-up HPV screening tests for women $\geq 30$ years old and ensure appropriate management

- Increase access to the diagnosis and to the treatment of cervical cancer and ensure palliative care with financial risk protection.

\section{We Agree To}

Undertake in all countries, in our various individual and collective capacities, to support efforts to promote the following actions for impact for girls and women worldwide:

- Advocate for national cervical cancer strategies which align with the global call to elimination
- Establish capacity-building efforts to expand the knowledge and skills of our membership to contribute to national elimination programs

- Support countries in rolling out the HPV vaccine for adolescent girls, cervical cancer screening and adequate management for older women

- Ensure that the quality of care and educational programs by the FIGO promote and support regional and national elimination ambitions

- Contribute with expertise to the emerging elimination work program, particularly supporting the WHO and the UNFPA updates of guidelines and technical guidance and their dissemination

- Harness FIGO collaborations and partnerships to promote cervical cancer elimination efforts in the context of the overall well-being of women.

Rio de Janeiro, October 18, 2018 